\title{
Emissions impacts of a modal shift: a case study of the Southern California ports region
}

\author{
Minyoung Park $^{*}$, Amelia Regan $^{* *}$ and Choon-Heon Yang ${ }^{* * *}$
}

\begin{abstract}
This paper presents a case study examining the emissions impacts of a modal shift from on-road trucks to rail for goods movement through the Southern California ports region, one of the severest nonattainment areas in terms of national air quality standards. Recent completion of the Alameda Corridor, a 20-mile rail expressway that connects the Ports of Long Beach and Los Angeles with rail mainlines near downtown Los Angeles, provides substantial reserve capacity for port traffic to be diverted from the severely congested road network to the rail line. On-road vehicles emissions were estimated using California mobile-source emissions model, 'EMFAC' that incorporates a set of emissions factors for each vehicle type and an estimate of vehicle activity. These emissions were then compared with the emissions generated from trains increased to carry freight volume diverted from truck traffic. On the basis of year 2000 traffic level, it was estimated that for a 20 percent modal shift of port traffic, mobile-source emissions can be reduced up to 0.86 tons for nitrogen oxides and $16 \mathrm{~kg}$ for particulate matter per day. The analysis results indicate that encouraging the modal shift for portrelated freight traffic should be an integral part of overall air quality improvement initiatives for the study area.
\end{abstract}

Keywords: air quality, alameda corridor, emissions, freight transportation, modal shift.

Submission Date: $02 / 10 / 2007$

Acceptance Date: 30/11/2007

*Corresponding author; Assistant Professor, Graduate School of Logistics, Inha University, Korea. Tel.: +82-32-8608237, Email: mypark@inha.ac.kr

**Associate Professor, Department of Civil and Environmental Engineering, University of California at Irvine, USA. Tel.: +1-949-824-1074, Email: aregan@uci.edu

${ }^{*} * * *$ Ph.D. Candidate, Department of Civil and Environmental Engineering, University of California at Irvine, USA. Tel.: +1-949-241-0772, Email: chyang@uci.edu 


\section{Introduction}

The Ports of Long Beach and Los Angeles (POLB/LA) in Southern California play a crucial role as a leading gateway for international and domestic freight movement in the United States. In 2004, these two ports together handled total 178 million tons of freight, accounting for nearly 60 percent of West Coast Port traffic (LACEDC, 2005). Fueled by demand for all types of goods due to a growing population, domestic economic growth, increased globalization, and reduced trade restrictions, freight volume through these two ports is expected to almost double by 2010, then double again by 2025 (LACMTA, 2002). The ability to efficiently handle cargo traffic through the ports complex is essential to the overall economic vitality of the region, the state and the nation.

Air quality preservation, however, presents a significant challenge for sustainable freight transportation in the region. Traffic congestion surrounding the ports in Southern California is already among the worst in the nation and continues to increase. This congestion poses an enormous ecological challenge to the environment of the region. While the region has made tremendous strides over the past 30 years towards controlling emissions from mobile and stationary sources, the South Coast Air Basin where the ports are located, is designated by the U.S. Environmental Protection Agency (EPA) as one of the severest non-attainment areas, far exceeding the national air quality standards (EPA, 2004). This makes it even harder to accommodate anticipated freight demand in the region because any projects for transportation improvement must demonstrate conformity with air quality goals.

Freight transportation in and out of the POLB/LA generally involves single mode trucking, railway operations, or intermodal operations of these two modes. Both truck and rail modes predominantly use diesel fuels, a major source of nitrogen oxides (NOx, an ozone precursor) and of particulate matter (PM). Trucks in particular are significant contributors to mobile-source air pollution in the region. Even with the adoption of new truck emissions standards, the share of total mobile-source NOx emissions in the South Coast Air Basin attributable to trucks is expected to increase from 44\% to 53\% between 2000 and 2010 (LACMTA, 2002). Furthermore, the expected increase in cargo throughput in the next few years will generate a considerable amount of truck traffic on the roads adjacent to the ports, consequently making the air quality even worse and threatening the future of freight transportation through the ports complex. In order to facilitate freight transportation in this area, thus, it is important to consider how to balance transportation improvements with environmental considerations, and thereby foster environmentally amiable practices.

In general, rail is regarded as the most fuel-efficient and environment-friendly form of freight transportation, compared to other modes. It has been documented that railroads' energy intensity measured in Btu per ton-mile is 346, which is comparable with 444 for waterborne carriage and 3,337 for trucks (AAR, 2005). This implies that if just 10 percent of the freight currently moved by trucks in the ports region were diverted to rail, hundreds of millions of gallons of fuel would be saved annually, leading to significant reduction in emissions of air pollutants. Considering the fact that a single train can carry the equivalent traffic load of 280 trucks on average (AAR, 2005), the opportunity to reduce emissions is more apparent. 
While there have been many efforts to estimate the relative emissions levels of different transportation modes, comparatively little information is available in the literature on empirical evidence that shows to what extent the emissions caused by a modal shift between alternative transportation modes are changed. With an application to Minnesota's waterways, Newstrand (1992) quantified the likely impacts of shifting four types of waterborne commodities from water to either trucks or rail in terms of fuel consumption and air quality as well as accident rates. The study showed that waterway for freight movement has fuel efficiency and emissions advantage over the truck and rail modes. On the other hand, Barth and Tadi (1996) examined the relative emissions levels of trucks and rail for freight movement along the California I-40 corridor on a link-by-link basis. They concluded that goods movement by rail produces lower emissions than by trucks on the I-40 corridor, except for NOx pollutant.

The purpose of this paper is to provide an additional case study that examines the emissions impacts of shifting port-related freight traffic from trucks to rail in the 20-mile region leading from the POLB/LA to downtown Los Angeles. Emissions of on-road vehicles including heavy-duty diesel trucks are estimated using a mobile-source emissions model, 'EMFAC' developed by the California Air Resources Board (CARB, 2002). Designed to estimate mobile on-road source emissions in California, the EMFAC model uses a modeling approach that incorporates a set of emissions factors for each vehicle type and an estimate of vehicle activity. These emissions are then compared with the emissions associated with increased freight trains carrying diverted freight from truck traffic. The difference can then be interpreted as the net air quality impact of the modal shift between truck and rail. The study results would help public agencies identify the most desirable mode in the study area in terms of air quality, and thus ensure that encouraging the modal shift for port traffic should be an integral part of overall air quality improvement initiatives for the region.

The paper is organized as follows. First, background information on the study area is presented briefly with a description of current transportation challenges faced by the ports region. This is followed by the methodology used to analyze the emissions estimation for on-road vehicles and freight locomotives. The emissions impact analysis of modal shift is then provided. Finally, the paper concludes with a discussion of potential strategies for air quality improvement for goods movement in the study area.

\section{Overview of study area}

The area selected for this study contains the southwestern, urbanized portions of Los Angeles, ranging from the POLB/LA to downtown Los Angeles. The region is one of the most active freight transportation areas in the United States, but there is a serious concern about how to secure adequate capacity to accommodate rapidly growing freight demand. The regional road system already faces severe congestion due to a large volume of vehicles operating in the region. Furthermore, high cost of land use and current built environment rule out any new capacity improvements. Forecasts of greater population and increasing international and domestic trade volume will lead inevitably to 
worsening congestion on the regional road network. Growing congestion on the roads, in turn, cause serious concerns about safety and air quality in the community.

On the other hand, the regional rail network has reserve capacity for port traffic that may be diverted from the roads. In April 2001, a 20-mile rail expressway called 'Alameda Corridor' opened for service connecting the POLB/LA with rail mainlines near downtown Los Angeles. Completion of the Alameda Corridor provides substantial improved rail capacity by eliminating delays for vehicles at 200 rail-street crossings, doubling rail speeds, and consolidating port-related traffic from four separate, low-speed branch lines. While designed to handle up to 150 trains per day, the Alameda Corridor has handled only an average of 35 train movements per day since its inauguration (ACTA, 2005).

As depicted in Figure 1, the Alameda Corridor runs parallel to the two major freeways, the Harbor Freeway (I-110) and the Long Beach Freeway (I-710). Both freeways are major corridors for goods movement that provide regional access to the POLB/LA, but approaching capacity limits. The freeways currently handle up to 40,000 trucks per day, accounting for nearly $45 \%$ of the freeway capacity (Caltrans, 2004). Inadequate capacity of the freeways may be overcome by the utilization of excess capacity of the Alameda Corridor. To facilitate the use of rail, the POLB/LA has invested in intermodal rail facilities that allow for the direct transfer of containers between ships and trains. About 48 percent of the port traffic is currently moved by a combination of truck and rail to other points across the nation (Meyer Mohaddes Associates et al., 2001). By reducing the number of short-distance truck trips by thousands per day, an initiative that intends to shift additional port traffic from on-road trucks to the Alameda Corridor could provide benefits in terms of congestion relief, greater safety, and improved regional air quality in the region.

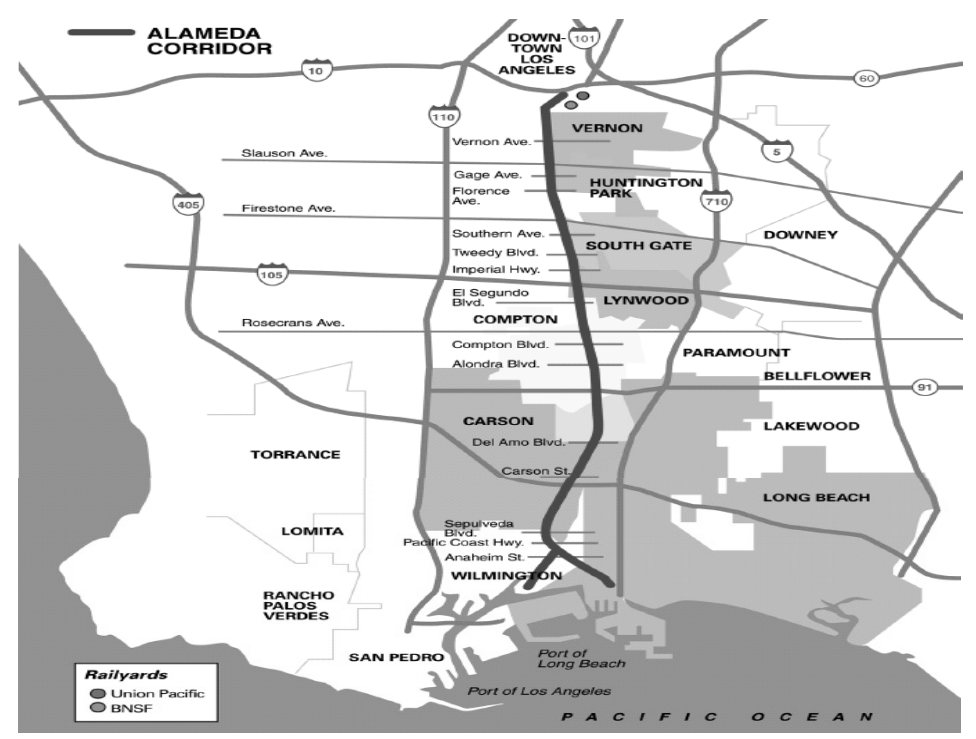

Source: www.acta.org

Figure 1. Overview of study area 
The quantification of the emissions benefits from the diversion of port traffic to the Alameda Corridor is of primary interest in this study. It is important to note that this study is done purely from an air quality standpoint and does not deal with traffic congestion alleviation and safety aspects of the modal shift. In addition, comparisons are made only for heavy-duty diesel trucks and locomotives involved in port-related goods movement within the study area. The following section addresses the methodology adopted for this study to evaluate the emissions impacts of the modal shift.

\section{Methodology}

Mobile source emissions inventory, in general, refers to the amount of air pollutants generated from mobile sources such as automobiles, trucks, buses, locomotives, and discharged into atmosphere a community's during a given time period. It is a function of motor vehicles' activities and resulting emissions, accounting for the amount of air pollutants attributable to both on-road and off-road sources. Over the years, stricter emission standards have been met with technological solutions of growing complexity. As a result, emissions estimation models have also grown both in size and complexity. Nevertheless, the basic methodology for emissions inventory estimation remains the same. The following equation describes the basic relationship between the parameters that determines a motor vehicle's emissions.

$$
E_{m t}=E R_{m} \times V A_{t}
$$

where

$$
\begin{aligned}
m & =\text { specific vehicle type or class; } \\
t & =\text { time frame under consideration; } \\
E R_{m} & =\text { emissions rate of vehicle } m \\
V A_{t} & =\text { vehicle activity during the specified time frame } t .
\end{aligned}
$$

As shown in equation (1), two major components are involved in calculating inventories of mobile source emissions: vehicle emissions rates expressed in grams per mile or grams per kilometer, and vehicle activity patterns often characterized by vehicle miles traveled (VMT). Vehicle emissions are generally a function of the speed and grade at which the vehicle is operating, and its physical characteristics such as engine size and horsepower. These factors affect the vehicle's emissions rates and the number of miles traveled by the vehicle during a specified time frame. The emissions factor estimated for a particular vehicle class serves as the $E R_{m}$ component of 
the equation. To calculate total emissions, total VMT accumulated by all vehicles in the vehicle class is estimated. The product of the emission factor and total VMT results in an estimate of the emissions contribution of the vehicle class during the time period in question. The emissions inventory model given above is basically employed for the emissions estimation of both on-road vehicles and locomotives in the analysis of modal shift emissions impacts.

\subsection{Data requirements and acquisition}

Network geometry and transportation demand matrix between origin and destination (OD) pairs in the network are primary inputs for the analysis of mobile source emissions. Physical transportation facilities are represented as a network consisting of a set of nodes and links, while spatial distribution patterns of transportation demand measured in vehicular traffic for a given time period are derived from conventional four-step demand forecasting models. Changes in vehicle emissions can be estimated under various network and/or operating conditions. We assumed in this study that the network configuration and transportation demand associated with the study area are given and thus are exogenous to our emissions impacts analysis.

The data were obtained from the Southern California Association of Governments (SCAG). Originally developed for a feasibility study of high occupancy vehicle lanes, the SCAG network includes all highways and major arterials in Southern California except for San Diego County. Since many portions of the network are beyond our study area, a sub-network for our study area was extracted from the SCAG network to enhance the resolution of emissions impacts. The extracted sub-network provides a baseline network used throughout all different evaluation scenarios in this study.

The extraction of the sub-network from the original network leads to the changes in the original OD demand matrix because redundant areas of original network are aggregated into external zones. The original OD demand matrix was developed for the base of year 2000 traffic level, considering six types of vehicles including drive-alone, carpool 2, carpool 3+, light-duty truck (LDT), medium-duty truck (MDT), and heavy-duty truck (HDT). For this study, however, the first three types of vehicles were aggregated into one type, referred to as "Auto" since changes in truck activity patterns are of primary interest. Consequently, four vehicle classes were considered in the final OD matrix used for the vehicle activity analysis. Each of vehicle classes has its unique OD table. A total of 7.7 million vehicles were generated to move from one place to another in the network during a peak hour, in which heavy-duty trucks account for only about 1.5 percent of the total vehicles.

It should be noted that the data obtained from SCAG are associated with the road network, thus can be used only for the estimation of on-road vehicles activity patterns. For the estimation of locomotive activity, the number of miles traveled by locomotives can be calculated by multiplying the current operating distance of the Alameda Corridor and the number of locomotives required to accommodate freight demand diverted from on-road trucks. These data were easily obtainable, making it possible to perform the locomotive activity analysis independently. 


\subsection{Emissions estimation of on-road vehicles}

The estimation process of on-road vehicle activity essentially involves a simulation study based on transportation demand models. TransCAD was selected as a tool for the analysis of vehicle activity, developed for transportation planning and system analysis that combines Geographic Information System with planning modeling and logistics applications. The program provides useful functions to easily store, regain, analyze, and envision all types of transportation and related geographic data in various ways.

The data files related to the sub-network and OD matrix were provided to the TransCAD model in order to measure on-road vehicles' activities. Given the transportation network and OD demand, a stochastic user-equilibrium traffic assignment was performed to simulate real-world traffic distribution pattern over the feasible routes between given OD pairs in the network. The results of the traffic assignment provide useful information on network-wide performance measures as well as link-based measures, including traffic volume, average speed and VMT. These measures can also be generated for each vehicle class, which is essential for the estimation of the emissions contribution by each of on-road vehicles.

Emissions rates for on-road vehicles were generated using EMFAC, a mobile source emissions model developed by the California Air Resources Board for the quantification of pollutants from on-road sources in California (CARB, 2002). In EMFAC, base emission rates are determined for a wide range of on-road vehicles through a set of correction factors. Different emissions rates can be obtained as a function of ambient temperature, relative humidity, and average speed. Los Angeles County was chosen as input for geographic area, and corresponding local characteristics of temperature and humidity were specified in the EMFAC model. Four pollutants were considered for the study, including carbon monoxide (CO), hydrocarbons (HC), oxides of nitrogen (NOx), and particulate matter (PM). To match with the data collected for the vehicle activity analysis, the year 2000 was chosen as the base year. Table 1 provides the base emissions factors for each vehicle class estimated using EMFAC, which will be basic inputs for the analysis of onroad vehicles emissions.

Table 1

Emission factors for on-road vehicles on the basis of year 2000

$(\mathrm{g} / \mathrm{mi})$

\begin{tabular}{l|c|c|c|c}
\hline & $\mathrm{HC}$ & $\mathrm{CO}$ & $\mathrm{NO}_{\mathrm{x}}$ & $\mathrm{PM}$ \\
\hline \hline Auto & 0.348 & 6.809 & 0.683 & 0.008 \\
Light-duty truck & 0.429 & 9.461 & 1.066 & 0.012 \\
Medium-duty truck & 0.465 & 8.782 & 1.501 & 0.014 \\
Heavy-duty truck & 0.775 & 8.507 & 12.972 & 0.278 \\
\hline
\end{tabular}




\subsection{Emissions estimation of freight locomotives}

As mentioned before, the approach adopted to estimate locomotive activity is unlike that applied to on-road vehicles. Freight trains along the Alameda Corridor are operated on a fixed operating distance of 20 miles. For the quantification of locomotive activity, it is necessary to estimate the total truckload freight tonnage diverted from on-road trucks to the Alameda Corridor. It is important to note that the number of locomotives currently operating on the corridor is not taken into account in the analysis of locomotive activity. The reason is that net emissions impacts of modal shift are dependent solely on the amount of emissions caused by the trains added to carry diverted freight from on-road.

Emission factors for diesel-powered locomotives were obtained from an EPA publication (EPA, 1997), in which two types of emissions rates are given for locomotives, one for line-haul movement and the other for switch-haul movement. Only emissions rates for line-haul locomotives were considered in this study since switching at the ports area does not take place due to the ports' role as either origin or destination of goods movement.

Table 2 presents the emission standards for locomotives established by the EPA, in which four separate sets of emission standards are given depending on the date a locomotive is first manufactured. The emission rates were originally measured in grams per brake horsepower-hour (g/bhp-hr), but can be also expressed as grams of pollutant emitted per gallon of fuel consumed (g/gal) using a conversion factor of $20.8 \mathrm{bhp}-\mathrm{hr} / \mathrm{gal}$.

Table 2

EPA emission standards for diesel locomotives

\begin{tabular}{l|c|c|c|c|c|c|c|c}
\hline & \multicolumn{2}{|c|}{$\mathrm{HC}$} & \multicolumn{2}{c|}{$\mathrm{CO}$} & \multicolumn{2}{c|}{$\mathrm{NO}_{\mathrm{x}}$} & \multicolumn{2}{c}{$\mathrm{PM}$} \\
\cline { 2 - 9 } & $\begin{array}{c}\mathrm{g} / \mathrm{bhp}- \\
\mathrm{hr}\end{array}$ & $\mathrm{g} / \mathrm{gal}$ & $\begin{array}{c}\mathrm{g} / \mathrm{bhp}- \\
\mathrm{hr}\end{array}$ & $\mathrm{g} / \mathrm{gal}$ & $\begin{array}{c}\mathrm{g} / \mathrm{bhp}- \\
\mathrm{hr}\end{array}$ & $\mathrm{g} / \mathrm{gal}$ & $\begin{array}{c}\text { g/bhp- } \\
\mathrm{hr}\end{array}$ & $\mathrm{g} / \mathrm{gal}$ \\
\hline \hline Pre-1973 locomotives & 0.48 & 10 & 1.28 & 26.6 & 13.0 & 270 & 0.32 & 6.7 \\
Tier 0 (1973-2001) & 0.48 & 10 & 1.28 & 26.6 & 8.6 & 178 & 0.32 & 6.7 \\
Tier 1 (2002-2004) & 0.47 & 9.8 & 1.28 & 26.6 & 6.7 & 139 & 0.32 & 6.7 \\
Tier 2 (after 2004) & 0.26 & 5.4 & 1.28 & 26.6 & 5.0 & 103 & 0.17 & 3.6 \\
\hline
\end{tabular}

Based on the assumption of equal proportion of Uncontrolled and Tier 0 local locomotive fleet mix, locomotive fleet-average emission factors were estimated as 10g/gal for $\mathrm{HC}, 26.6 \mathrm{~g} / \mathrm{gal}$ for CO, $224 \mathrm{~g} / \mathrm{gal}$ for $\mathrm{NO}_{\mathrm{x}}$ and $6.7 \mathrm{~g} / \mathrm{gal}$ for PM for calendar year 2000. For the purpose of comparing the emissions inventories of on-road vehicles and locomotives, the locomotive emissions factors then were converted to grams per mile using the following equation developed for this study. 


$$
E R_{m i}=E R_{g a l} \times \frac{(T \times A P F)}{A F E}
$$

where

$$
\begin{aligned}
E R_{m i} & =\text { emissions rates, in grams per mile; } \\
E R_{g a l} & =\text { emissions rates, in grams per gallon; } \\
T & =\text { number of trucks reduced by modal shift; } \\
A P F & =\text { average payload factor of a truck, in tons; } \\
A F E & =\text { average fuel efficiency of locomotives, in ton-miles per gallon. }
\end{aligned}
$$

The product of the number of trucks reduced and average payload factor generates the total weight of freight volume shifted to railroad. This term divided by the average fuel efficiency produces the amount of fuel required to transport a distance of a mile, which serves as a conversion factor for changing emissions rate into grams per mile. The average payload factor was assumed to be 14,158 pounds for a heavy-duty truck (VRPA Technologies and Cambridge Systematics, 2002), which is equivalent to 6.4 tons, while 405 ton-miles per gallon was applied for the average fuel efficiency of locomotives (AAR, 2005). By multiplying with the operating distance of locomotives, the emissions factors for locomotives derived from the equation were used to estimate total emissions caused by locomotives. Note that the number of trucks reduced by the modal shift can be determined depending on the scenarios considered, which will be presented in the following section.

\subsection{Net emissions impact}

On-road vehicles emissions are then compared with the emissions associated with increased freight trains carrying freight volume diverted from trucks. The difference can be interpreted as the net emissions impacts of the modal shift from truck to rail. Overall procedure to analyze the emissions impacts of modal shift from road to rail is illustrated in Figure 2. 


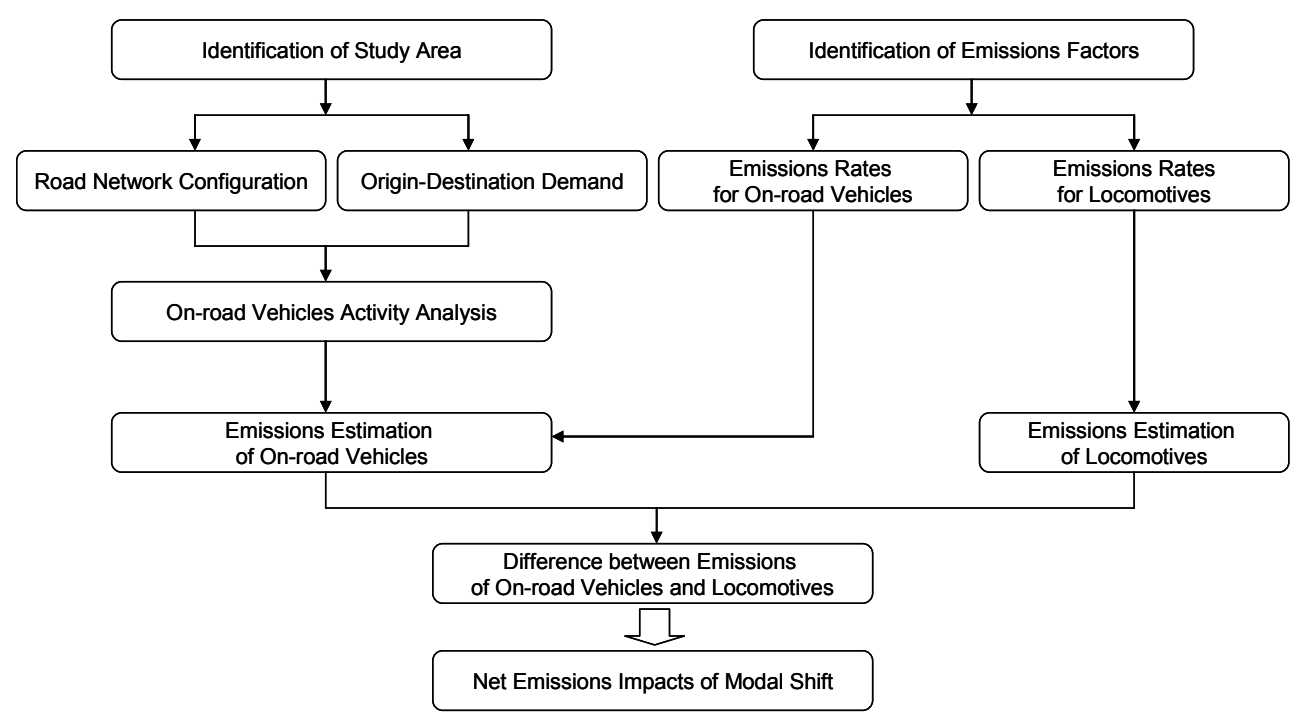

Figure 2. Overall procedure for the emissions impact analysis

\section{Emissions impact analysis}

Using the methodology described in the preceding section, we estimated the activities of onroad vehicles and locomotives and subsequent emissions. This section provides the results of the emissions impact analysis.

\subsection{Scenarios}

To quantify the emissions impacts of a modal shift, it is necessary to consider a potential diversion rate between alternative transportation modes. Among four types of on-road vehicles considered, the feasible modal diversion associated with port-related freight movement is more likely to occur in heavy-duty truck traffic moving into and out of port area. For study purposes, it was assumed that some of heavy-duty truckload traffic is shifted from road to rail with a greater emphasis in short-haul rail service, while the volumes of other types of on-road vehicles remain the same. This assumption leads to changes in traffic condition of the baseline network created for the study, which form the basis for scenarios that are examined in this study.

Scenarios considered in this study are 1) current baseline condition, 2) 10\% reduction, and 3) $20 \%$ reduction in the volume of heavy-duty trucks. The original SCAG data suggests that 1,949 heavy-duty trucks are generated from and destined to the port area during the most congested time period of the day. Thus, the potential $10 \%$ reduction in HDT volume in our analysis means $10 \%$ diversion of port-related truck traffic to the Alameda Corridor, which is equivalent to 195 trucks 
perhour.

It should be noted that the potential diversion of truck traffic depends in part on the reserve capacity of rail network in the study area that can accommodate the equivalent freight load of diverted trucks. As mentioned earlier, the Alameda Corridor is currently operating 35 trains per day, while it was designed to handle up to 150 trains per day. Considering the operating hours of 12 hours, the number of daily operating trains is equivalent to 3 trains per hour and its maximum hourly rate is about 13 trains. This implies that the existing rail network has a reserve capacity of as many as 10 trains per hour. Provided that a single train can carry the equivalent traffic load of 280 trucks, the reserve capacity of the Alameda Corridor is equivalent to 2,800 truckloads. This figure shows that the current rail network has enough near-term capacity to accommodate anticipated freight demand through the ports area.

\subsection{Changes in on-road vehicle VMT}

Changes in heavy-duty truck volume result in different measures of the number of miles traveled by on-road vehicles. To estimate the changes in VMT for each vehicle type, different sets of OD matrices for heavy-duty trucks that reflect different scenarios were created and compiled into the TransCAD, in which traffic assignments were performed.

Table 3 provides total VMT measures estimated for each vehicle class under different scenarios. The results show that the movement of heavy-duty vehicles was reduced by 7,800 in VMT for 20\% modal shift, while the changes in VMT for other vehicle types range from 28 VMT in MDT to 2,723 VMT in Auto for the same scenario. The effects of reduced HDT volume on VMT estimates for other vehicle types are seen less significant than those on heavy trucks. This result may be mainly due to the small portion of HDT volume, which accounts for only $1.5 \%$ of total number of vehicles in the original SCAG data.

Table 3

VMT estimates for on-road vehicles under different scenarios

\begin{tabular}{l|c|c|c|c}
\hline & Auto & LDT & MDT & HDT \\
\hline \hline Baseline & $4,694,896$ & 55,221 & 48,041 & 65,703 \\
$10 \%$ reduction & $4,693,545$ & 55,205 & 48,027 & 61,803 \\
$20 \%$ reduction & $4,692,173$ & 55,189 & 48,013 & 57,903 \\
\hline
\end{tabular}

Note: The VMT estimates were based on the year 2000 traffic level.

\subsection{Emissions estimation results}

With the emissions factors estimated for on-road vehicles and locomotives, the estimated onroad vehicles VMT and added ton-miles for locomotives were used to calculate total emissions 
produced from two types of transportation modes on an hourly basis. The total system-wide emissions for $\mathrm{HC}, \mathrm{CO}, \mathrm{NO}_{\mathrm{x}}$ and $\mathrm{PM}$ pollutants were then estimated for three different modal shift rates. Comparisons were made between reduced on-road emissions and added locomotive emissions to measure the net emissions impacts of modal shift.

As summarized in Table 4, for a $20 \%$ modal shift, $\mathrm{NO}_{\mathrm{x}}$ emissions were reduced by 103.6 $\mathrm{kg} / \mathrm{hr}$ from on-road vehicles, while locomotives added to carry the same amount of truckload freight produced $31.7 \mathrm{~kg} / \mathrm{hr}$. The estimated net change in $\mathrm{NO}_{\mathrm{x}}$ was a reduction of $71.9 \mathrm{~kg} / \mathrm{hr}$, indicating that goods moved by rail generate 3.3 times lower emissions in $\mathrm{NO}_{\mathrm{x}}$ pollutant than by truck. For the same scenario, the net emissions reduction of other pollutants in $\mathrm{kg} / \mathrm{hr}$ varies from 1.3 in PM to 5.7 in $\mathrm{HC}$ and 82.2 in CO. It is interesting to observe that the reduction in $\mathrm{CO}$ emissions appears to be most significant in terms of absolute values in net change, but from a perspective of overall system-wide effect, more significant emissions benefits come from the reduction in PM and $\mathrm{NO}_{\mathrm{x}}$ pollutants, reduced by $2.23 \%$ and $1.67 \%$, respectively. These results suggest that all other conditions being equal, rail is a more desirable mode than truck in terms of air quality improvement.

Table 4

Potential emissions impacts of modal shift

$(\mathrm{kg} / \mathrm{hr})$

\begin{tabular}{l|c|c|c|c|c|c|c|c}
\hline & \multicolumn{4}{|c|}{$10 \%$ Reduction } & \multicolumn{5}{c}{$20 \%$ Reduction } \\
\cline { 2 - 9 } & $\mathrm{HC}$ & $\mathrm{CO}$ & $\mathrm{NO}_{\mathrm{x}}$ & $\mathrm{PM}$ & $\mathrm{HC}$ & $\mathrm{CO}$ & $\mathrm{NO}_{\mathrm{x}}$ & $\mathrm{PM}$ \\
\hline \hline Reduced on-road emissions & 3.5 & 42.7 & 51.6 & 1.1 & 7.1 & 85.8 & 103.6 & 2.2 \\
Added locomotive emissions & 0.7 & 1.8 & 15.8 & 0.5 & 1.4 & 3.6 & 31.7 & 0.9 \\
Net change & 2.8 & 40.9 & 35.8 & 0.6 & 5.7 & 82.2 & 71.9 & 1.3 \\
System-wide reduction (\%) & 0.13 & 0.09 & 0.83 & 1.10 & 0.27 & 0.19 & 1.67 & 2.23 \\
\hline
\end{tabular}

\section{Conclusion and discussion}

In this paper, we have presented a case study examining the emissions impacts of a modal shift from on-road trucks to rail for goods movement through the Southern California ports region. The overall emissions impacts of shifting port traffic from on-road trucks to rail appear to be positive. The analysis results show that nearly 0.86 tons per day of $\mathrm{NO}_{\mathrm{x}}$ emissions can be eliminated when a $20 \%$ modal shift is realized in the study area under the assumption that there are 12 operating hours in each day. Considering an operational work year of 300 days, this is equivalent to almost 260 tons of reduction in $\mathrm{NO}_{\mathrm{x}}$ emission per year. Similarly, we estimate that a $20 \%$ mode shift would result in reduction in PM of $15.6 \mathrm{~kg}$, CO of $986 \mathrm{~kg}$ and $\mathrm{HC}$ of $68.4 \mathrm{~kg}$ per day. While these numbers may sound small, such changes over such a small geographic area and for such a small amount of diverted freight are significant when compared to the size of the South Coast Air Basin. Therefore, encouraging the modal shift of port traffic should be an integral part of overall air quality improvement initiatives for the study area. 
Although the emissions benefits expected from the modal shift in the study area could be considerable, such a large-scale diversion is not likely to occur in the foreseeable future without substantial policy intervention. There is a common perception in the freight community that while trains afford many advantages over trucks in terms of lower emissions and fuel consumption, accident rates, and labor requirements, they only make sense operationally over distances of 500 miles (around $800 \mathrm{~km}$ ). Furthermore, costs associated with terminal operations and drayage (local pickup and delivery via truck) introduce overhead that must be offset increases in efficiency of rail transportation to be time and cost competitive with on-road trucking.

In recent years, however, there is a growing interest in consideration of rail transportation for even short-haul goods movement near congested urban areas. The recent emergence of a shuttle rail service for short-haul freight movements applied in a corridor where the road network is highly congested and existing rail capacity is underutilized, serves as an example (Resor, 2004). This is mainly due to the rapidly growing concerns in the areas about increases in congestion, deterioration of air quality and difficulty in capacity expansion, all being major barriers to efficient freight transportation. This is especially the case in the Los Angeles metropolitan area where the Ports complex-of-interest is located.

The promotion of the use of such a shuttle rail service in our study area through the Alameda Corridor will require both positive and negative inducements. An attempt to offer an incentive for cargo owners to move containers by rail and/or during off-peak hours at the Los Angeles/Long Beach ports provides a good example (PierPASS, 2004). Under continued pressure to adjust operations in ways that mitigate traffic and air quality impacts of port operations and in response to threatened regulatory legislation, terminal operators have agreed to implement a voluntary program of extended gate hours. Scheduled to begin in early 2005, the proposed program called 'PierPass' assesses a 'Traffic Mitigation Fee' on all loaded containers entering or exiting the marine terminal gates by road during peak hours between $8 \mathrm{AM}$ and $5 \mathrm{PM}$. These fees are intended to pay the costs of extended operations at the ports, but are not charged for the movement of goods by rail and/or during evening and weekends. Shifting port traffic to off-peak hours and alternative rail mode is seen as an opportunity to alleviate daytime congestion on local highways, thereby reducing mobile-source emissions. It also has the potential to increase the throughput of the marine terminals, which have struggled to cope with increased container volume and port labor shortages.

In order to substantially improve air quality near the Southern California ports complex, a variety of public policy alternatives should be examined and several of these should be implemented in concert. Together with modal shift and off-peak operations, the following are some potential strategies that may be effective in solving environmental problems in the ports region with respect to freight transportation:

A truck appointment system, designed to limit vehicle idling at the terminal gates;

Intermodal rail improvement, which allows for the direct transfer of containers between ships and trains;

Truck-only facilities, such as truck-only lanes that separate slowly-moving trucks from other high-speed vehicles to stabilize traffic flow on the highways;

Applications of advanced technologies, such as Automatic Vehicle Identification and Virtual Weigh-inMotion that allow electronic screening and enforcement as trucks move into and out of the Ports complex. 


\section{Acknowledgements}

This research was partially supported by the University of California Transportation Center (UCTC) and the California Department of Transportation (Caltrans). The authors gratefully acknowledge that support. The authors also thank the Southern California Association of Governments (SCAG) for their cooperation and support with our data requirements. Any opinions expressed are those of the authors and not necessarily those of the UCTC or Caltrans.

\section{References}

Alameda Corridor Transportation Authority (ACTA). 2007. Fact sheet. www.acta.org/ newsroom_factsheet.htm accessed by July 2007.

Association of American Railroads (AAR). 2005. Railroads: building a cleaner environment. www.aar.org/ViewContent.asp?Content_ID=894. accessed by July 2007.

Barth, M. J. and R. Tadi Ramakrishna. 1996. Emissions comparison between truck and rail: Case Study of California I-40. Transportation Research Record: Journal of the Transportation Research Board. No. 1520. TRB. National Research Council. Washington D.C. pp. 44-52.

California Air Resources Board (CARB). 2002. EMFAC 2002 user's guide. CARB, Sacramento, CA. www.arb.ca.gov/msei/on-road/latest_version.htm. accessed by July 2005.

California Department of Transportation (Caltrans). 2004. 2003 Annual average daily truck traffic on the California State highway system. Division of Traffic Operations, Caltrans, CA. www.dot.ca.gov/hq/traffops/saferesr/trafdata/. accessed by July 2007.

Los Angeles County Economic Development Corporation (LACEDC). 2005. International trade trends and impacts: the Southern California region. A technical report.www.laedc.org/data/pdf/. accessed by July 2005.

Los Angeles County Metropolitan Transportation Authority (LACMTA). 2002. Southern California freight management cases study. A technical report, LACMTA, CA.

Meyer, Mohaddes Associates, et al. 2001. Ports of Long Beach and Los Angeles transportation study. A technical report prepared for the Ports of Long Beach and Los Angeles.

Newstrand, M. W. 1992. Environmental impacts of a modal shift. Transportation Research Record: Journal of the Transportation Research Board, No. 1333. TRB. National Research Council. Washington D.C. pp. 9-12.

Pier PASS Inc. 2004. Pier PASS and the off-peak Hours Program. www.pierpass.org. accessed by July 2005 .

Resor, R. 2004. Short-haul rail intermodal: can it compete with truck?. Presented at the 83rd TRB Annual Meeting Alternative Freight Capacity Workshop. TRB. National Research Council. Washington D.C. January 11-15. 
U.S. Environmental Protection Agency (EPA). 1997. Emission factors for locomotives. Publication No. EPA 420-F-97-051. www.epa.gov/otaq/locomotv.htm. accessed by July 2007.

U.S. Environmental Protection Agency (EPA). 2004. The green book non-attainment areas for criteria pollutants. www.epa.gov/oar/oaqps/greenbk/. accessed by July 2007.

VRPA Technologies and Cambridge Systematics Inc. 2002. Goods movement truck count study. A technical report prepared for Southern California Association of Governments. Los Angeles, CA. 